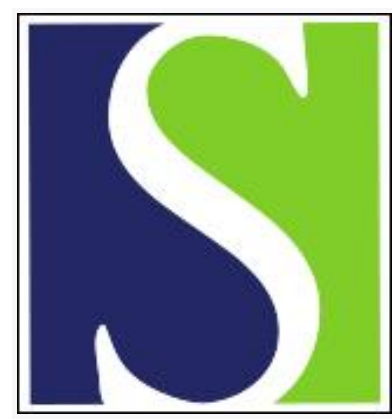

Scand J Work Environ Health Online-first -article

https://doi.org/10.5271/sjweh.2914

Published online: 29 Mar 2010

Fitness, work, and leisure-time physical activity and ischaemic heart disease and all-cause mortality among men with pre-existing cardiovascular disease

by Holtermann A, Mortensen OS, Burr H, Søgaard K, Gyntelberg F, Suadicani P

Affiliation: National Research Centre for the Working Environment, Lersø Parkallé 105, 2100 Copenhagen Ø, Denmark. aho@nrcwe.dk

Refers to the following texts of the Journal: 2010;36(5):357-365 2009;35(6):466-474 2007;33(6):405-424

The following articles refer to this text: $2010 ; 36(5): 357-365$; 2010;36(5):349-355; 2011;37(1):6-29; 2015;41(2):124-139; 2015;41(6):519-528

Key terms: all-cause mortality; cardiovascular disease; cardiovascular health; fitness; health; ischaemic heart disease; leisure-time; leisure-time physical activity; man; men; mortality; occupational health; occupational physical activity; physical activity; physical fitness; work

This article in PubMed: www.ncbi.nlm.nih.gov/pubmed/20352173 


\title{
Fitness, work, and leisure-time physical activity and ischaemic heart disease and all-cause mortality among men with pre-existing cardiovascular disease
}

\author{
by Andreas Holtermann, PhD, ${ }^{1}$ Ole Steen Mortensen, PhD, ${ }^{1,2}$ Hermann Burr, PhD, ${ }^{1}$ Karen Søgaard, PhD, ${ }^{3}$ \\ Finn Gyntelberg, DMSc, ${ }^{2}$ Poul Suadicani, DMSc ${ }^{2}$
}

\begin{abstract}
Holtermann A, Mortensen OS, Burr H, Søgaard K, Gyntelberg F, Suadicani P. Fitness, work, and leisure-time physical activity and ischaemic heart disease and all-cause mortality among men with pre-existing cardiovascular disease. Scand J Work Environ Health. 2010;36(5):366-372.
\end{abstract}

\begin{abstract}
Objective Our aim was to study the relative impact of physical fitness, physical demands at work, and physical activity during leisure time on ischaemic heart disease (IHD) and all-cause mortality among employed men with pre-existing cardiovascular disease (CVD).

Method We carried out a 30-year follow-up of the Copenhagen Male Study of 274 gainfully employed men, aged 40-59 years who had a history of CVD (ie, myocardial infarction, angina pectoris, and intermittent claudication). We estimated physical fitness [maximal oxygen consumption $\left(\mathrm{VO}_{2} \mathrm{Max}\right)$ ] using the Åstrand cycling test and determined physical work demands and leisure-time physical activity using a self-reported questionnaire.

Results Among 274 men with a history of CVD, 93 men died from IHD. Using male employees with a history of CVD and a low level of fitness as the reference group, our Cox analyses - adjusted for age, blood pressure, smoking, alcohol consumption, body mass index, diabetes, hypertension, physical work demands, leisure-time physical activity, and social class - showed a substantially reduced risk for IHD mortality among employees who were intermediately fit $\left[\mathrm{VO}_{2} \mathrm{Max}\right.$ range $25-36$; hazard ratio (HR) $0.54,95 \%$ confidence interval $(95 \% \mathrm{CI}) \mathrm{CI}$ $0.32-0.93$ ] and highly fit $\left(\mathrm{VO}_{2} \mathrm{Max}\right.$ range $37-50$; $\left.\mathrm{HR} 0.28,95 \% \mathrm{CI} 0.12-0.66\right)$. We found a positive, but statistically non-significant association between physical demands at work and all-cause mortality.
\end{abstract}

Conclusion Among gainfully employed men with pre-existing CVD, a high physical fitness was associated with a substantially reduced risk for IHD and all-cause mortality.

Key terms cardiovascular health; occupational health; occupational physical activity; physical fitness.

In two recent publications from the Copenhagen Male Study, we found that men exposed to high physical demands at work were at an increased risk of mortality from ischaemic heart disease (IHD) $(1,2)$. This increased risk was particularly pronounced among men who were physically inactive during leisure time and those who had a low physical fitness. The men included in these prospective studies $(1,2)$ were free from overt cardiovascular disease (CVD) at baseline.

The medical literature consistently shows that physical exercise training reduces the risk of CVD and allcause mortality among persons with a history of CVD (3-5). In contrast, the influence of a high physical work activity on CVD mortality among employees with
CVD is less established and needs further investigation. Recently, Krause and colleagues (6) observed that high physical demands at work enhanced the risk for atherosclerosis, in particular among men with CVD, even after controlling for physical fitness. Since people with CVD, despite their disease, are often exposed to physical work demands resulting in excessive levels of relative aerobic strain (6), it seems relevant to investigate whether high levels of physical workload are associated with increased mortality risks for employees with a history of myocardial infarction or symptoms of CVD.

A low level of physical fitness is a well-documented predictor of CVD and all-cause mortality among patients with CVD (7-9). However, no previous long-term studies

1 National Research Centre for the Working Environment, Copenhagen, Denmark.

2 The Copenhagen Male Study, Epidemiological Research Unit, Department of Occupational and Environmental Medicine, Bispebjerg University Hospital, Copenhagen NV, Denmark.

3 Institute of Sports Science and Clinical Biomechanics, University of Southern Denmark, Odense M, Denmark.

Correspondence to: Dr A Holtermann, National Research Centre for the Working Environment, Lersø Parkallé 105, 2100 Copenhagen Ø, Denmark. [E-mail: aho@nrcwe.dk] 
have examined if employees remaining at work with pre-existing CVD combined with a low level of physical fitness have an increased risk for CVD mortality.

Modification of physical work demands, leisure-time physical activity and physical fitness among employees with pre-existing CVD may be important for individual counselling and secondary prevention. Accordingly, the aim of this study was to investigate the predictive role of physical work demands, leisure-time physical activity, and physical fitness for the risk of IHD and all-cause mortality among employees with pre-existing CVD.

\section{Methods}

\section{Study population}

The Copenhagen Male Study was established in 19701971 and comprised 5249 (87\% of those invited to participate) male employees, aged 40-59 years, from 14 companies, covering the railway, public road construction, military, postal, telephone, customs, national bank, and medical industry sectors $(10,11)$.

The examination consisted of a questionnaire, a short interview, and a clinical examination including measurements of height, weight, and blood pressure. Indirect measurement of physical fitness (maximal oxygen consumption, $\mathrm{VO}_{2} \mathrm{Max}$ ) was performed with a bicycle ergometer. Thirty-five men with orthopaedic problems, who were unable to perform the bicycle test, were excluded from the study.

From the questionnaire, we obtained information about working conditions, lifestyle, and general health, including history of myocardial infarction, angina pectoris, and intermittent claudication. The information given in the questionnaire was clarified with each subject in the ensuing interview. Details on the questionnaire have already been published (12). A number of these factors are elaborated in more detail below.

\section{Eligibility}

The study group comprised 274 men with a history of myocardial infarction, symptoms of angina pectoris, or intermittent claudication (hereafter pre-existing CVD) and 4966 men with no such history. With respect to all variables included, missing values ranged from $0-2.7 \%$.

\section{Cardiovascular disease history}

Information on history of myocardial infarction was based on a simple question: "Do you have any personal history of heart thrombosis?" The answer options were "yes" and "no". Angina pectoris diagnosis was based on a modified version of the Rose questionnaire. To be classified as suffering from angina pectoris, the study participant should have reported yes to all of the following four questions: (i) "Have you ever felt chest pain?" (ii) "Do you get chest pain when walking up stairs or hurrying?" (iii) "Does the pain or the discomfort disappear if you stand still?" and (iv) "Does the pain/discomfort go away within 10 minutes?" To be classified as suffering from intermittent claudication, the study participant should have reported yes to all of the following four questions: (i) "Do you experience pain in your legs when walking?" (ii) "Is the pain located in your calf?" (iii) "Does the pain occur when you are walking up stairs or hurrying?" and (iv) "Does the pain go away within ten minutes if you stand still or walk more slowly?"

\section{Physical activity at work, general description}

Physical activity during work was estimated by the following question: "Which description most precisely covers your pattern of physical activity at work?" Groups were defined according to the following responses: (i) You are mainly sedentary and do not walk much around at your workplace, for example, desk work, and work including assembling of minor parts (group 1); (ii) You walk around quite a bit at your workplace but do not have to carry heavy items, eg, light industrial work, non-sedentary office work, inspection and the like (group 2); (iii) Most of the time you walk, and you often have to walk up stairs and lift various items. Examples include mail delivery and construction work (group 3); (iv) You have heavy physical work. You carry heavy burdens and carry out physically strenuous work, eg, work including digging and shoveling (group 4). In the analyses, physical activity was defined as follows: group $1=$ low, group $2=$ medium; group $3=$ high (since only $2.4 \%$ belonged to group 4 , groups 3 and 4 were pooled) and are referred to as high.

\section{Strenuous work}

Strenuous work was estimated from the question: "Do you perform strenuous work (work resulting in sweating)?" The answer options were: "often", "occasionally", and "seldom or never" and coded as follows: $1=$ seldom or never, $2=$ occasionally, and $3=$ often.

\section{Physical work activity, combined variable}

An additional variable was constructed in order to further distinguish between the presence or absence of physically demanding work. Summing up the values from the aforementioned questions on physical activity and strenuous work gave values ranging from 2-6. A low combined score of 2 was defined as "low physical work demands", a score of 3 or 4 was defined as "moderate physical work demands", and a score of 5 or 6 was defined as "high physical work demands". 


\section{Physical activity during leisure time}

In order to determine this factor, the questionnaire asked "Which description most precisely covers your pattern of physical activity at leisure time?" with the following possible responses: (i) You are mainly sedentary, for example, you read, watch television, go to the cinema. In general you spend most of your leisure time performing sedentary tasks (group 1); (ii) You go for a walk, use your bicycle a little or perform activity for at least 4 hours per week, for example, light gardening, leisure-time building activity, table tennis and bowling (group 2); (iii) You are an active athlete, eg, run, play tennis or badminton for at least 3 hours/week. If you frequently perform heavy gardening, you also belong to this group (group 3); (iv) You take part in competitive sports, swim, play European football, handball or run long distances regularly several times per week (group 4).

In the analyses, the level of physical activity during leisure time was defined as group $1=$ low, group $2=$ moderate, and group $3=$ high (since only $0.4 \%$ belonged to group 4, groups 3 and 4 were pooled).

\section{Physical fitness}

Heart rate was measured during submaximal bicycle work in a steady state with the aid of a stopwatch and stethoscope. The loads used were 100, 150, and $200 \mathrm{~W}$. One, two, or in a few cases three different loads were used. The load chosen in each case was determined by the weight and age of the person or heart rate during the first minute of the test; we determined the $\mathrm{VO}_{2} \mathrm{Max}$ using Åstrand's nomogram (13). The correlation between directly and indirectly measured $\mathrm{VO}_{2} \mathrm{Max}$ is high. The method used has previously been described in detail (10).

\section{Lifestyle factors}

The male workers reported if they were current smokers, previously smoked, or had never smoked. In addition, participants reported their daily average alcohol consumption as the number of alcoholic beverages consumed per day in the following categories: $0,1-2$, $3-5,6-10$, and $>10$.

\section{Clinical and health-related factors}

Based on height and weight measurements, body mass index (BMI) was calculated as $\mathrm{kg} / \mathrm{m}^{2}$. Blood pressure was measured with the subject seated and after at least five minutes rest. A $12 \mathrm{~cm}$ wide, $26 \mathrm{~cm}$ long cuff was firmly and evenly applied to the right upper arm with the lower edge of the cuff placed $2 \mathrm{~cm}$ antecubitally. Diastolic blood pressure was recorded at the point where the Korotkoff sounds disappeared (phase 5). In addition, the participants were asked if they received treatment for either hypertension or diabetes from their physician or elsewhere. The answer options were yes or no.

\section{Social class}

The men were divided into five social classes according to a system originally elaborated by Svalastoga and later adjusted by Hansen $(28,29)$ This classification system is based on education level and job position in terms of the number of subordinates. Typical jobs in the study cohort were: (i) officer, civil engineer, office executive, or head of department (social class I); (ii) head clerk or engineer (social class II); engine driver or train guard (social class III); machine fitter in a telephone company (social class IV); and unskilled laborer, mechanic, or driver (social class V).

\section{End-points}

We obtained information on death diagnoses between the period 1970-1971 to the end of 2001 from official national registers. The IHD mortality diagnoses included International Classification of Diseases' codes ICD-8: 410-14, and (from 1994) ICD-10: I20-I25.

\section{Statistical analysis}

We performed basic statistical analyses, Chi-squared analysis (likelihood ratio), unpaired t-test, and regression analyses. We estimated hazard ratios (HR) using $\exp (\beta)$, where $\beta$ is the hazard coefficient for the variable of interest in a Cox's proportional hazards regression model with the maximum likelihood ratio method. A varying number of men were included in the survival analysis (table 2) due to differences in missing values for each particular analysis. We took, a priori, as significant a two-sided probability value of $\mathrm{P}<0.05$.

\section{Results}

Of the 274 men with pre-existing CVD, 210 died including 93 from IHD. Table 1 shows the lifestyle and other characteristics of the men according to their history of CVD. Employees with a pre-existing history of CVD had a lower level of physical fitness, were less likely to have a medium level of leisure-time physical activity, and more likely to be previous or current smokers, suffer from hypertension (both systolic and diastolic blood pressure), belong to lower social classes, and be older than asymptomatic employees. Minor, but significant differences in physical fitness, alcohol consumption, BMI, and age between the CVD disease and symptom 
Table 1. Distribution of cardiovascular risk factors and other characteristics according to history of cardiovascular disease (ie, myocardial infarction, angina pectoris, or intermittent claudication). [SD=standard deviation; Freq=frequency; $\mathrm{VO}_{2} \mathrm{Max}=$ maximal oxygen consumption]

\begin{tabular}{|c|c|c|c|c|c|c|c|c|c|c|c|c|}
\hline & \multicolumn{9}{|c|}{ History of cardiovascular disease } & \multirow{2}{*}{\multicolumn{3}{|c|}{$\begin{array}{l}\text { No history of } \\
\text { cardiovascular disease } \\
(\mathrm{N}=4966)\end{array}$}} \\
\hline & \multicolumn{3}{|c|}{$\begin{array}{l}\text { Myocardial infarction } \\
\quad(\mathrm{N}=74)\end{array}$} & \multicolumn{3}{|c|}{$\begin{array}{l}\text { Angina pectoris } \\
\quad(N=165)\end{array}$} & \multicolumn{3}{|c|}{$\begin{array}{l}\text { Intermittent claudication } \\
\qquad(\mathrm{N}=105)\end{array}$} & & & \\
\hline & Mean & SD & Freq $(\%)$ & Mean & SD & Freq $(\%)$ & Mean & SD & Freq $(\%)$ & Mean & SD & Freq $(\%)$ \\
\hline \multicolumn{13}{|l|}{ Cardiovascular disease } \\
\hline Myocardial infarction & . & . & 100.0 & . & . & 20.0 & . & . & 8.7 & . & . & 0 \\
\hline Angina pectoris & . & . & 44.6 & . & . & 100.0 & . & . & 27.6 & . & . & 0 \\
\hline Intermittent claudication & . & . & 12.2 & . & . & 17.6 & . & . & 100.0 & . & . & 0 \\
\hline \multicolumn{13}{|l|}{ Physical activity at work } \\
\hline Low & . & . & 30.4 & . & . & $22.5^{a}$ & . & . & 22.7 & . & . & 26.0 \\
\hline Medium & . & . & 52.2 & . & . & $47.5^{\mathrm{a}}$ & . & . & 53.6 & . & . & 55.9 \\
\hline High & . & . & 17.4 & . & . & $30.0^{a}$ & . & . & 23.7 & . & . & 18.1 \\
\hline \multicolumn{13}{|l|}{ Leisure-time physical activity } \\
\hline Low & . & . & $20.5^{b}$ & . & . & $26.2^{c}$ & . & . & $32.7^{c}$ & . & . & 16.8 \\
\hline Medium & . & . & $76.7^{\mathrm{b}}$ & . & . & $71.3^{c}$ & . & . & $67.3^{c}$ & . & . & 72.7 \\
\hline High & · & . & $2.7^{b}$ & . & . & $2.4^{\mathrm{c}}$ & . & . & $0^{c}$ & . & . & 10.4 \\
\hline Physical fitness $\left(\mathrm{VO}_{2} \mathrm{Max}\right)$ & $29.8^{c}$ & 5.5 & . & $30.6^{c}$ & 6.3 & . & $29.7^{c}$ & 7.0 & $\cdot$ & 33.0 & 7.3 & · \\
\hline Lowest quintile, 15-26 range & . & . & $34.8^{c}$ & . & . & $28.7^{c}$ & . & . & $38.6^{c}$ & . & . & 18.0 \\
\hline Medium quintiles, 27-38 range & . & . & $59.1^{\mathrm{c}}$ & . & . & $59.2^{c}$ & . & . & $49.5^{c}$ & . & . & 61.4 \\
\hline Highest quintiles, 39-78 range & . & . & $6.1^{\mathrm{c}}$ & . & . & $12.1^{\mathrm{c}}$ & . & . & $11.9^{c}$ & . & . & 20.5 \\
\hline \multicolumn{13}{|l|}{ Lifestyle factors 1970-1971 } \\
\hline \multicolumn{13}{|l|}{ Smoker } \\
\hline Current & . & . & $71.6^{b}$ & . & . & $73.2^{a}$ & . & . & $83.8^{c}$ & . & . & 71.8 \\
\hline Previous & . & . & $25.7^{b}$ & . & . & $23.8^{\mathrm{a}}$ & . & . & $15.2^{c}$ & . & . & 19.1 \\
\hline Never & . & . & $2.7^{b}$ & . & . & $3.0^{\mathrm{a}}$ & . & . & $1.0^{\mathrm{c}}$ & . & . & 9.1 \\
\hline \multicolumn{13}{|l|}{ Alcohol, beverages per 24 hours } \\
\hline 0 & . & . & 39.2 & . & . & 31.5 & . & . & $23.8^{c}$ & . & . & 33.8 \\
\hline $1-2$ & . & . & 41.9 & . & . & 46.1 & . & . & $41.0^{\mathrm{c}}$ & . & . & 47.3 \\
\hline $3-5$ & . & . & 14.9 & . & . & 18.8 & . & . & $31.4^{\mathrm{c}}$ & . & . & 15.7 \\
\hline$\geq 6$ & . & . & 4.1 & . & . & 3.6 & . & . & $3.8^{c}$ & . & . & 3.1 \\
\hline \multicolumn{13}{|l|}{ Clinical risk factors } \\
\hline Diabetes (treatment of) & . & . & 1.4 & . & . & 0.6 & . & . & $3.8^{b}$ & . & . & 0.8 \\
\hline Systolic blood pressure (mm Hg) & $143.2^{c}$ & 22.7 & . & $139.6^{c}$ & 23.9 & . & $145.6^{c}$ & 26.3 & . & 134.7 & 19.0 & . \\
\hline Diastolic blood pressure $(\mathrm{mm} \mathrm{Hg})$ & $88.2^{c}$ & 13.0 & & $85.9^{c}$ & 13.6 & & $87.1^{c}$ & 12.4 & . & 83.0 & 11.6 & . \\
\hline Hypertension (treatment of) & . & . & $10.8^{c}$ & . & . & $7.3^{c}$ & . & . & 2.9 & . & . & 1.6 \\
\hline Body mass index $\left(\mathrm{kg} / \mathrm{m}^{2}\right)$ & 25.0 & 2.6 & & $25.8^{b}$ & 2.9 & & $26.4^{\mathrm{c}}$ & 3.5 & . & 25.3 & 3.0 & . \\
\hline \multicolumn{13}{|l|}{ Other characteristics } \\
\hline Low social class (classes IV/V) & · & . & 52.7 & . & · & $63.0^{b}$ & . & . & $67.6^{a}$ & . & . & 51.0 \\
\hline Age (years) & $51.9^{c}$ & 5.1 & & $51.3^{c}$ & 5.0 & & $51.6^{c}$ & 5.0 & . & 48.6 & 5.3 & · \\
\hline
\end{tabular}

a P-values of Chi-square test (likelihood ratio) or unpaired Student's t-tests: $P \leq 0.01$.

b P-values of Chi-square test (likelihood ratio) or unpaired Student's t-tests: $P \leq 0.05$.

c P-values of Chi-square test (likelihood ratio) or unpaired Student's t-tests: $\mathrm{P} \leq 0.001$.

categories were observed. We also found larger, significant differences in physical activity at work, leisure-time physical activity, prevalence of previous or current smokers, diabetes, systolic and diastolic blood pressure, hypertension, and social class. The total number of employees in the CVD disease and symptom categories exceeded 274 due to the overlap between the two.

Table 2 shows the association of baseline physical fitness, level of leisure-time physical activity, and physical work demands with the risk of IHD and all-cause mortality among employees with pre-existing CVD. Employees with pre-existing CVD and a high level of physical fitness had a $72 \%$ lower risk of IHD mortality [fully adjusted hazard ratio (HR) $0.28,95 \%$ confidence interval $(95 \% \mathrm{CI}) 0.12-0.66]$ and a $59 \%$ lower risk of all-cause mortality (fully adjusted HR $0.41,95 \%$ CI 0.23-0.73) compared to employees with pre-existing CVD and a low level of physical fitness.

Employees with pre-existing CVD, who are highly physically active during leisure time, did not have a significantly different risk for IHD and all-cause mortality (fully adjusted HR 1.14, 95\% CI 0.25-5.26, and HR $1.16,95 \%$ CI $0.43-3.18$, respectively) compared to employees with pre-existing CVD and a low level of leisure-time physical activity.

Employees with pre-existing CVD and high physical 
Table 2. Physical fitness and physical activity during work and leisure time as predictors of ischaemic heart disease and all-cause mortality during 1970-71 to end of 2001 among men with history of myocardial infarction, angina pectoris, or intermittent claudication at baseline ( $\mathrm{N}=274$ ). [HR=hazard ratio; $95 \% \mathrm{Cl}=95 \%$ confidence interval; $\mathrm{VO}_{2} \mathrm{Max}=$ maximal oxygen consumption]

\begin{tabular}{|c|c|c|c|c|c|c|}
\hline \multirow[b]{3}{*}{ Ischaemic heart disease mortality } & \multicolumn{2}{|c|}{ Mortality } & \multirow[t]{2}{*}{$\mathrm{HR}^{\mathrm{a}}$} & \multirow[t]{2}{*}{$95 \% \mathrm{Cl}$} & \multirow[t]{2}{*}{$\mathrm{HR}^{\mathrm{b}}$} & \multirow[t]{2}{*}{$95 \% \mathrm{Cl}$} \\
\hline & $\mathrm{N}$ & $\%$ & & & & \\
\hline & & & & & & \\
\hline \multicolumn{7}{|l|}{ Physical fitness, $\mathrm{VO}_{2} \mathrm{Max}$} \\
\hline $\begin{array}{l}\text { Lowest quintile, } 15-24 \text { range }(N=58) \\
\text { Medium quintiles, } 25-36 \text { range }(N=156) \\
\text { Highest quintiles, } 37-50 \text { range }(N=48)\end{array}$ & $\begin{array}{l}27 \\
47 \\
11\end{array}$ & $\begin{array}{l}46.6 \\
30.1 \\
22.9\end{array}$ & $\begin{array}{l}1.00 \\
0.59^{c} \\
0.46^{c}\end{array}$ & $\begin{array}{r}\cdot \\
0.36-0.95 \\
0.22-0.96\end{array}$ & $\begin{array}{l}1.00 \\
0.54^{c} \\
0.28^{d}\end{array}$ & $\begin{array}{r}\cdot \\
0.32-0.93 \\
0.12-0.66\end{array}$ \\
\hline \multicolumn{7}{|l|}{ Leisure time physical activity } \\
\hline $\begin{array}{l}\text { Low }(N=70) \\
\text { Moderate }(N=190) \\
\text { High }(N=6\end{array}$ & $\begin{array}{r}28 \\
59 \\
2\end{array}$ & $\begin{array}{l}40.0 \\
31.2 \\
33.3\end{array}$ & $\begin{array}{l}1.00 \\
0.80 \\
0.98\end{array}$ & $\begin{array}{r}. \\
0.51-1.26 \\
0.23-4.14\end{array}$ & $\begin{array}{l}1.00 \\
1.01 \\
1.14\end{array}$ & $\begin{array}{r}0 \\
0.59-1.74 \\
0.25-5.26\end{array}$ \\
\hline \multicolumn{7}{|l|}{ Physical work demands } \\
\hline $\begin{array}{l}\text { Low }(\mathrm{N}=61) \\
\text { Moderate }(\mathrm{N}=134) \\
\text { High }(\mathrm{N}=64)\end{array}$ & $\begin{array}{l}24 \\
40 \\
22\end{array}$ & $\begin{array}{l}39.3 \\
30.1 \\
34.4\end{array}$ & $\begin{array}{l}1.00 \\
0.85 \\
0.98\end{array}$ & $\begin{array}{r}0.51-1.41 \\
0.55-1.76\end{array}$ & $\begin{array}{l}1.00 \\
0.73 \\
1.05\end{array}$ & $\begin{array}{r}0.40-1.30 \\
0.51-2.17\end{array}$ \\
\hline \multicolumn{7}{|l|}{ All-cause mortality } \\
\hline \multicolumn{7}{|l|}{ Physical fitness, $\mathrm{VO}_{2} \mathrm{Max}$} \\
\hline $\begin{array}{l}\text { Lowest quintile, } 15-24 \text { range }(\mathrm{N}=58) \\
\text { Medium quintiles, } 25-36 \text { range }(\mathrm{N}=156) \\
\text { Highest quintiles, } 37-50 \text { range }(\mathrm{N}=48)\end{array}$ & $\begin{array}{r}51 \\
122 \\
25\end{array}$ & $\begin{array}{l}87.9 \\
78.7 \\
52.1\end{array}$ & $\begin{array}{l}1.00 \\
0.79 \\
0.51^{c}\end{array}$ & $\begin{array}{r}\cdot \\
0.57-1.10 \\
0.31-0.84\end{array}$ & $\begin{array}{l}1.00 \\
0.78 \\
0.41^{d}\end{array}$ & $\begin{array}{r}0.54-1.13 \\
0.23-0.73\end{array}$ \\
\hline \multicolumn{7}{|l|}{ Leisure time physical activity } \\
\hline $\begin{array}{l}\text { Low }(N=70) \\
\text { Moderate }(N=190) \\
\text { High }(N=6\end{array}$ & $\begin{array}{r}56 \\
141 \\
5\end{array}$ & $\begin{array}{l}80.0 \\
74.6 \\
83.3\end{array}$ & $\begin{array}{l}1.00 \\
0.93 \\
1.32\end{array}$ & $\begin{array}{r}\cdot \\
0.68-1.27 \\
0.53-3.31\end{array}$ & $\begin{array}{l}1.00 \\
1.06 \\
1.16\end{array}$ & $\begin{array}{r}\text {. } \\
0.74-1.51 \\
0.43-3.18\end{array}$ \\
\hline \multicolumn{7}{|l|}{ Physical work demands } \\
\hline $\begin{array}{l}\text { Low }(N=61) \\
\text { Moderate }(N=134) \\
\text { High }(N=64)\end{array}$ & $\begin{array}{r}46 \\
100 \\
51\end{array}$ & $\begin{array}{l}75.4 \\
75.2 \\
79.2\end{array}$ & $\begin{array}{l}1.00 \\
1.16 \\
1.24\end{array}$ & $\begin{array}{r}. \\
0.81-1.64 \\
0.83-1.85\end{array}$ & $\begin{array}{l}1.00 \\
1.09 \\
1.36\end{array}$ & $\begin{array}{r}. \\
0.73-1.62 \\
0.84-2.21\end{array}$ \\
\hline
\end{tabular}

${ }^{a}$ Adjusted for age.

${ }^{b}$ Fully adjusted model including simultaneously all relevant predictors and confounders: age, physical fitness, leisure-time physical activity, physical work demands, smoking habits, alcohol use, diabetes (treatment for), body mass index and social class.

c $P \leq 0.05$.

d $P \leq 0.01$.

work demands did not have a substantially different risk for IHD mortality (fully adjusted HR $1.05,95 \%$ CI $0.51-$ 2.17), but showed a $36 \%$ increased risk for all-cause mortality (fully adjusted HR 1.36 , CI $0.84-2.21$ ) compared to employees with pre-existing CVD and low physical work demands, although these estimates were not statistically significant due to the relatively small sample size.

\section{Discussion}

Among gainfully employed men with pre-existing CVD, a high physical fitness was associated with a substantially reduced risk for IHD and all-cause mortality, using employees with a low level of physical fitness as the reference group. Leisure-time physical activity and physical work demands did not significantly modify the risk for IHD and all-cause mortality among the employees with pre-existing CVD. However, the observed effect sizes are compatible with a positive association between high physical work demands and mortality. Studies with improved exposure measures and more statistical power are needed to confirm or contradict these findings.

Several previous studies have demonstrated the importance of physical fitness for the risk of CVD and all-cause mortality among asymptomatic populations (16-19), and CVD patients (7-9). This is the first long-term study examining if employees with preexisting CVD and a low level of physical fitness have an increased risk for CVD mortality. The findings of $46 \%$ and $72 \%$ reduced risk for employees with pre-existing CVD and, respectively, intermediate and high levels of physical fitness, compared with employees with a low level of physical fitness confirms that physical fitness is an independent powerful predictor for IHD and all-cause mortality among employees with pre-existing CVD. The 
observed importance of physical fitness for the risk of IHD and all-cause mortality among employees with pre-existing CVD correspond with the highly appreciated value of quantifying the physical fitness of patients with CVD (8).

The risk for IHD and all-cause mortality decreased in a parallel dose-response manner with increasing physical fitness among asymptomatic employees and those with pre-existing CVD. This finding is in accordance with a previous study of Myers and colleagues (7) observing a similar importance of physical fitness for all-cause mortality among men with and without pre-existing CVD.

The reduced risk of CVD and all-cause mortality from exercise training programs among patients with CVD is well documented (3-5). Among the employees with pre-existing CVD in this study, we did not find any significant effects of leisure-time physical activity for the risk of IHD and all-cause mortality. This may be influenced by the fact that there were very few employees with a high level of leisure-time physical activity in our study. However, the result corresponds with the previous finding that only physical fitness, and not self-reported leisure-time physical activity predict CVD mortality among asymptomatic persons (20). Moreover, this finding may be explained by the fact that reduced risk for mortality from physical exercise training is strongly related to the corresponding improvement in physical fitness (21). Because leisure-time physical activity was also not significant in the age-adjusted model, it does not seem to be an independent predictor for IHD and all-cause mortality among employees with pre-existing CVD.

In a recent study, Krause and colleagues (6) observed that high physical demands at work particularly enhanced the risk for atherosclerosis among male employees with CVD. This finding could not be explained by low physical fitness alone because the physical work demands were controlled for physical fitness in the multivariate analyses (6). In a previous study in the Copenhagen Male Study, we found a doubled risk for IHD mortality from high physical demands at work among the leastfit asymptomatic employees and a $75 \%$ increased risk among those with medium fitness, in stark contrast to the most-fit asymptomatic employees who had no increased risk for IHD mortality from high physical demands at work (2). In this study, we did not find any significant association between physical work demands and IHD, but a substantial (although not statistical significant) association with all-cause mortality. These inconsistent results and lack of statistical significance may be attributed to the relatively small number of subjects and relatively crude categorical measures used in our study. Another explanation of the finding may be that employees remaining at work, despite having a pre-existing CVD condition, constitute a selected, relatively healthy group.

\section{Methodological considerations}

In interpreting the results of this study, it is important to bear in mind that the disease history may per se have influenced the degree of physical activity - both in the workplace and during leisure hours. Moreover, the employees remaining at work despite pre-existing CVD may be a particular, selected group among men with CVD. Furthermore, we do not know how long the employees remain in the workforce after the baseline measurement. The non-significant relations between physical activity during leisure time and at work and IHD and all-cause mortality may be a result of the limited study population. Therefore, it is necessary to examine the influence of physical activity at work and during leisure time on IHD and all-cause mortality in a larger population of employees with pre-existing CVD.

Directly measured physical fitness is more precise than indirectly estimated physical fitness (22). However, indirect estimates using cycling ergometry have been shown to correspond well with direct measures of physical fitness among patients with heart failure (23). A methodological aspect of this study is that the occupational and leisure-time physical activity information was based on self-assessment, which invariably entails some degree of misclassification (24). However, no technical equipment for measuring daily physical activity at work and during leisure time was available in 1970, at least not in Denmark.

The limitations of this study included the lack of precise continuous and repeated exposure measures during a very long follow-up period and, therefore, possible exposure misclassification. Moreover, we would like to mention that the outcome measures in this study and in the study of Krause (6) are not directly comparable, where particularly the non-symptomatic and objectively measured outcome of atherosclerosis in the study of Krause (6) is less vulnerable to health-based selection and misclassification biases.

The study population of the Copenhagen Male Study comprised urban, Danish male workers, aged 40-59 years in 1970-1971. It is unknown whether the findings of this study are relevant also for females, younger workers, and workers from other (eg, rural) communities and nationalities with pre-existing CVD.

\section{Concluding remarks}

The strong independent predictive value of physical fitness for IHD and all-cause mortality among employees remaining at work despite pre-existing CVD supports the great clinical value of physical fitness. 


\section{References}

1. Holtermann A, Mortensen OS, Burr H, Søgaard K, Gyntelberg F, Suadicani P. The interplay between physical activity at work and during leisure time - risk of ischemic heart disease and allcause mortality in middle-aged Caucasian men. Scand J Work Environ Health. 2009;35(6):466-74.

2. Holtermann A, Mortensen OS, Burr H, Søgaard K, Gyntelberg F, Suadicani P. Physical demands at work, physical fitness, and 30-year ischaemic heart disease and all-cause mortality in the Copenhagen Male Study. Scand J Work Environ Health. 2010;36(5):357-65.

3. Taylor RS, Brown A, Ebrahim S, Jolliffe J, Noorani H, Rees K, et al. Exercise-based rehabilitation for patients with coronary heart disease: systematic review and meta-analysis of randomized controlled trials. Am J Med. 2004;116(10):682-92.

4. Jolliffe JA, Rees K, Taylor RS, Oldridge N, Ebrahim S. Exercise-based rehabilitation for coronary heart disease. Cochrane Database Syst Rev. 2001;(1).

5. Leon AS, Franklin BA, Costa F, Balady GJ, Berra KA, Stewart KJ, et al. Cardiac rehabilitation and secondary prevention of coronary heart disease: an American Heart Association Scientific Statement from the Council on Clinical Cardiology (Subcommittee on Exercise, Cardiac Rehabilitation, and Prevention) and the Council on Nutrition, Physical Activity, and Metabolism (Subcommittee on Physical Activity), in collaboration with the American Association of Cardiovascular and Pulmonary Rehabilitation. Circulation. 2005;111(3):369-76.

6. Krause N, Brand RJ, Kaplan GA, Kauhanen J, Malla S, Tuomainen T-P, et al. Occupational physical activity, energy expenditure and 11-year progression of carotid atherosclerosis. Scand J Work Environ Health. 2007;33(6):405-24.

7. Myers J, Prakash M, Froelicher V, Do D, Partington S, Atwood JE. Exercise capacity and mortality among men referred for exercise testing. N Engl J Med. 2002;346(11):793-801.

8. Kavanagh T, Mertens DJ, Hamm LF, Beyene J, Kennedy $\mathrm{J}$, Corey P, et al. Prediction of long-term prognosis in 12169 men referred for cardiac rehabilitation. Circulation. 2002;106(6):666-71.

9. Kavanagh T, Mertens DJ, Hamm LF, Beyene J, Kennedy J, Corey $\mathrm{P}$, et al. Peak oxygen intake and cardiac mortality in women referred for cardiac rehabilitation. J Am Coll Cardiol. 2003;42(12):2139-43.

10. Gyntelberg F. Physical fitness and coronary heart-disease male residents in copenhagen aged 40-59. Dan Med Bull. 1973;20(1):1-4.

11. Gyntelberg F. One-year and 2-years incidence of myocardialinfarction in copenhagen males aged 40-59. Dan Med Bull. $1975 ; 22(2): 81-4$.
12. Hein HO, Suadicani P, Gyntelberg F. Ischaemic heart disease incidence by social class and form of smoking: the Copenhagen Male Study-17 years' follow-up. J Intern Med .1992;231(5):477-83.

13. Åstrand P-O, Rodahl K. Textbook of work physiology: physiological bases of exercise. New York (NY): McGraw-Hill Book Company; 1986.

14. Svalastoga K. Prestige, class and mobility. Copenhagen: Munksgaard; 1959.

15. Hansen EJ. Social groups in Denmark. Copenhagen: The Danish National Centre for Social Research; 1984.

16. Blair SN, Kohl HW, Paffenbarger RS, Clark DG, Cooper KH, Gibbons LW. Physical fitness and all-cause mortality - a prospective-study of healthy-men and women. JAMA. 1989;262(17):2395-401.

17. Blair SN, Kohl HW, Barlow CE, Paffenbarger RS, Gibbons LW, Macera CA. Changes in physical fitness and all-cause mortality - a prospective-study of healthy and unhealthy men. JAMA. 1995;273(14):1093-8.

18. Ekelund LG, Haskell WL, Johnson JL, Whaley FS, Criqui MH, Sheps DS. Physical fitness as a predictor of cardiovascular mortality in asymptomatic north-american men - the lipid research clinics mortality follow-up-study. N Engl J Med.1988;319(21):1379-84.

19. Hein HO, Suadicani P, Gyntelberg F. Physical-fitness or physical activity as a predictor of ischemic heart disease - a 17-year follow-up in the Copenhagen Male Study. J Intern Med. 1992;232(6):471-9.

20. Talbot LA, Morrell CH, Metter EJ, Fleg JL. Comparison of cardiorespiratory fitness versus leisure time physical activity as predictors of coronary events in men aged $\leq 65$ years and $>65$ years. Am J Cardiol. 2002;89(10):1187-92.

21. Vanhees L, Fagard R, Thijs L, Amery A. Prognostic value of training-induced change in peak exercise capacity in patients with myocardial infarcts and patients with coronary-bypass surgery. Am J Cardiol. 1995;76(14):1014-9.

22. Arena R, Myers J, Williams MA, Gulati M, Kligfield P, Balady GJ, et al. Assessment of functional capacity in clinical and research settings: a scientific statement from the American Heart Association Committee on Exercise, Rehabilitation, and Prevention of the Council on Clinical Cardiology and the Council on Cardiovascular Nursing. Circulation. 2007;116(3):329-43.

23. Kaminsky LA, Brubaker PH, Peaker B, Kitzman DW. Prediction of peak oxygen uptake from cycle exercise test work level in heart failure patients $\geq 65$ years of age. Am J Cardiol. 2000;85(11):1385-7.

24. Sallis JF, Saelens BE. Assessment of physical activity by selfreport: status, limitations, and future directions. Res Q Exerc Sport. 2000;71(2):S1-S14.

Received for publication: 16 December 2009 